\title{
A headlight on liquid biopsies: a challenging tool for breast cancer management
}

\author{
Daniela Massihnia $^{1}$ - Alessandro Perez ${ }^{1} \cdot$ Viviana Bazan $^{1} \cdot$ Giuseppe Bronte $^{1}$. \\ Marta Castiglia $^{1}$ - Daniele Fanale ${ }^{1}$ - Nadia Barraco ${ }^{1}$ - Antonina Cangemi ${ }^{1}$. \\ Florinda Di Piazza $^{1}$ - Valentina Calò ${ }^{1} \cdot$ Sergio Rizzo $^{1} \cdot$ Giuseppe Cicero $^{1}$. \\ Gianni Pantuso ${ }^{1} \cdot$ Antonio Russo $^{1}$
}

Received: 7 October 2015 / Accepted: 13 January 2016

(C) International Society of Oncology and BioMarkers (ISOBM) 2016
Keywords Liquid biopsy $\cdot$ Breast cancer $\cdot$ Circulating tumor cells $\cdot$ CTCs $\cdot$ Circulating tumor DNA $\cdot$ ctDNA

\section{Introduction}

Breast cancer is the most common carcinoma and one of the leading causes of cancer-related deaths in women aged between 35 and 75 years $[1,2]$. Although breast cancer seems to be most often sporadic, about $5-10 \%$ of new cases are hereditary. Indeed, about half of these would be associated with germline mutations occurring on codifying DNA sequences which determine a high risk of developing the disease during life and for this reason called "susceptibility genes" [3, 4].

The two major identified susceptibility genes are the tumor suppressor genes BRCA1 and BRCA2 involved in DNA double strand break repair trough the homologous recombination (HR) pathway. Germline mutations in these genes cause genetic instability that enhance the development of additional mutations in other pivotal genes involved in cell cycle control and many others cellular processes [4-7]. Gene expression profiling studies, performed by microarray analysis, highlighted the molecular heterogeneity of breast cancers, allowing the identification of different molecular subgroups with similar characteristics. Thus, based on the gene expression profiles, they were classified into four distinct subtypes: luminal A, luminal B, human epithelial growth factor receptor 2 (HER2) overexpressing, and basal-like [8]. Furthermore, immunohistochemical characterization of the aforementioned subtypes on the basis of ER, PR, and HER2 expression is shown in Table 1. Current ESMO guidelines on primary breast cancer management consider this classification and implement it with Ki-67 levels. The cutoff to distinguish high from low levels of ki-67 is by $30 \%$ [9]. Histologically, breast 
Table 1 Immunohistochemical profile of breast cancer subtypes

\begin{tabular}{llll}
\hline Luminal A & Luminal B & HER2+/ER- & Basal like \\
\hline$\cdot$ ER + & $\bullet$ ER + & $\bullet$ ER - & $\bullet$ ER- \\
$\bullet$ and/or PR+ & $\bullet$ and/or PR+ & $\bullet$ PR- & $\bullet$ PR- \\
$\bullet$ HER2- & $\bullet$ HER2 + & $\bullet$ HER2 + & $\bullet$ HER2-
\end{tabular}

$E R$ estrogen receptor, $P R$ progesterone receptor, HER 2 receptor type 2 for EGF

cancer can be divided into in situ and invasive carcinoma, both of which can be further subclassified into ductal and lobular carcinomas [10]. Triple negative breast cancer (TNBC) represents $15-20 \%$ of all breast cancers. This unfavorable cancer histotype lacks in the expression of estrogen, progesterone, and human epidermal growth factor receptor-2 receptors. Moreover, it usually presents at young age (age $<50$ years), advanced stage at first diagnosis, unfavorable outcome, grade 3 , high proliferative index, and higher risk of metastases [11, 12].

Even though breast cancer represents the second leading cause of cancer-related death among women, a significant proportion of patients can be treated by surgery only or surgery and adjuvant systemic therapies. Despite the improvements in disease management, mortality is still high due to the emergence of distant metastasis. With the introduction of new approaches, as well as next-generation sequencing (NGS), it starts to be clear that clonal evolution occurs, among a cell population, within the primary tumor and it is mainly due to intra-tumor heterogeneity [13]. Furthermore, anticancer therapies may also cause a selective acquisition of new genetic alterations.

Another relevant drawback in luminal breast cancer is that the metastatic event can appear years after first diagnosis. This might be referred as "tumor dormancy," it means that cancer cells may colonize earlier distant sites but stay dormant until they do not accumulate enough genetic and/or epigenetic modifications that allow their awakening from "dormancy" [14]. Two different possible scenarios can be forecasted for explaining the metastatic event. According to the first scenario, tumor cells leave the primary site to colonize distant organs only if they acquire a totally competence to generate a metastatic development. In the second case, "almost normal epithelial cells" leave preneoplastic lesions earlier and evolve simultaneously with the primary tumor cell population [15].

Currently in the clinical practice, it is very difficult to find a reliable tool to follow tumor evolution over time, and this lack is probably the main reason of treatment failure whether administered at wrong time points during the course of disease. Liquid biopsy may represent the solution to the aforementioned problems. Recent findings demonstrate that circulating tumor cells (CTCs) and circulating tumor DNA (ctDNA) are detectable in blood samples even at early stage disease.
Moreover, technological improvements in CTCs and ctDNA isolation, detection, and analysis are paving the way for their introduction in the current clinical practice. Moreover, new insight into the nature and severity of breast cancers could arise from small extracellular vesicles. Among the extracellular bodies, the interest of the scientific community in exosomes biology is daily growing. Indeed, exosomes are small vesicles (diameter 40-100 nm) involved in mediating a cross-talk between the extracellular matrix and the cell acting as a shuttle of many compounds as nucleic acids and proteins $[16,17]$. Indeed, these could represent a new intriguing diagnostic marker because of their possible involvement in a multitude of cellular processes as well as the event of tumor growth, metastasis, and not less notable, drug resistance as effect of anticancer drugs removal from the breast cancer cells $[17,18]$.

Few data have been available yet about the assessment of serum microRNAs in breast cancer as it has been carried out in other malignancies. The development of microRNA panels in serum would add relevant information for breast cancer classification along with messenger RNA (mRNA) expression levels in tissue and ctDNA panels in serum [19-22].

The review is focused on the clinical relevance of liquid biopsy in breast cancer. We will provide an update concerning CTCs and ctDNA utility as a tool for breast cancer patients monitoring during the course of disease.

\section{An overview on main signaling pathways involved in breast cancer}

Mutation gain in somatic cells is the pivotal mechanism through which cancer cells alter normal signaling pathways [23], in addition to other modifications such as epigenetic variations which are primarily influenced by the local microenvironment and germline genetic variations.

Cancer whole-genome studies highlighted a still growing number of involved somatic mutations, most of which have not yet a known biological function. The accumulation of mutations within a cancerous and/or precancerous cell population is a dynamic process not fully understood, and until now, several pathways have been identified as responsible for the process of mammary carcinogenesis.

The evaluation of estrogen, progesterone, and epidermal growth factor type 2 receptors (ER, PgR, and HER2, respectively) is widely used in clinical practice in order to obtain prognostic and predictive information [24]. Also, several other markers, such as B-cell lymphoma 2, androgen receptor, EGF, phosphatase and tensin homolog (PTEN), and phosphatidylinositol 3-kinase (PI3K), may have prognostic value in breast cancer. Several studies have reported that mutations in PI3K are associated with lower recurrence and mortality 
rates $[25,26]$. PI3K/Akt/mTOR pathway is often altered in patients with breast cancer. This pathway controls several biological activities within the cell, and its activation is one of the fundamental downstream molecular events following tyrosine kinase growth factor receptor activation [27]. The first event is the activation of PI3K, which, when not inhibited by PTEN, phosphorylates and activates AKT localizing it in the plasma membrane [28]. AKT can have a number of downstream effects by activating different substrates such as the mammalian target of rapamycin (mTOR) whose substrate is S6 Kinase 1 (p70S6K) [29-31] (Fig. 1).

PI3K mutations are more frequent in node-negative (not spread to nearby lymph nodes), ER-positive, and Her2- negative patients, and are generally related to a favorable clinical outcome. Several studies have reported that mutations in PI3K are associated with lower recurrence and mortality rates [25, 26]. PI3K mutations are very high recurrent genetic alterations in breast cancers with a rate of 20-40\% in these cancers [32]. The PI3K/AKT/mTOR pathway plays a central role in regulating cell proliferation, growth, apoptosis, and motility. The PI3K enzyme is a heterodimer composed of a regulatory ( $p 85$ ) and a catalytic subunit (p110), and it is activated after the dimerization and auto-phosphorylation of tyrosine kinase receptors, such as HER2. Following its activation, PI3K is able to phosphorylate phosphatydilinositol 4,5-trisphosphate (PIP2) in phosphatydilinositol 3,4,5-trisphosphate (PIP3) that is the main actor for the activation of PKB/AKT [33, 34]. Under physiological conditions, the PIP3 levels are tightly regulated by specific phosphatases, such as PTEN. Alteration in the PI3K/AKT pathway, due to loss or gain of expression as well as genetic changes of its members, is a pivotal event toward a malignant transformation, as already well described in literature. Several studies have demonstrated that the gene encoding the PI3K catalytic subunit $\mathrm{p} 110 \mathrm{a}$ (PI3KCA) is mutated in different cancers [35]. Activating mutations in the $\mathrm{p} 110 \alpha$ catalytic subunit of PI3K has been also described in 9-45\% of breast cancers [32]. The preferred mutational "hot spots" for PI3KCA are predominantly exons 9 and exon 20; mutations of these exons determine the following amino acid substitutions: H1047R, E545K, and E542K. This mutations account for $70-80 \%$ of PI3KCA alterations in breast cancer [36]. These hot spot mutations are known to

Fig. 1 Activation mechanism of $\mathrm{PI} 3 \mathrm{~K} / \mathrm{Akt} / \mathrm{mTOR}$ signaling pathway

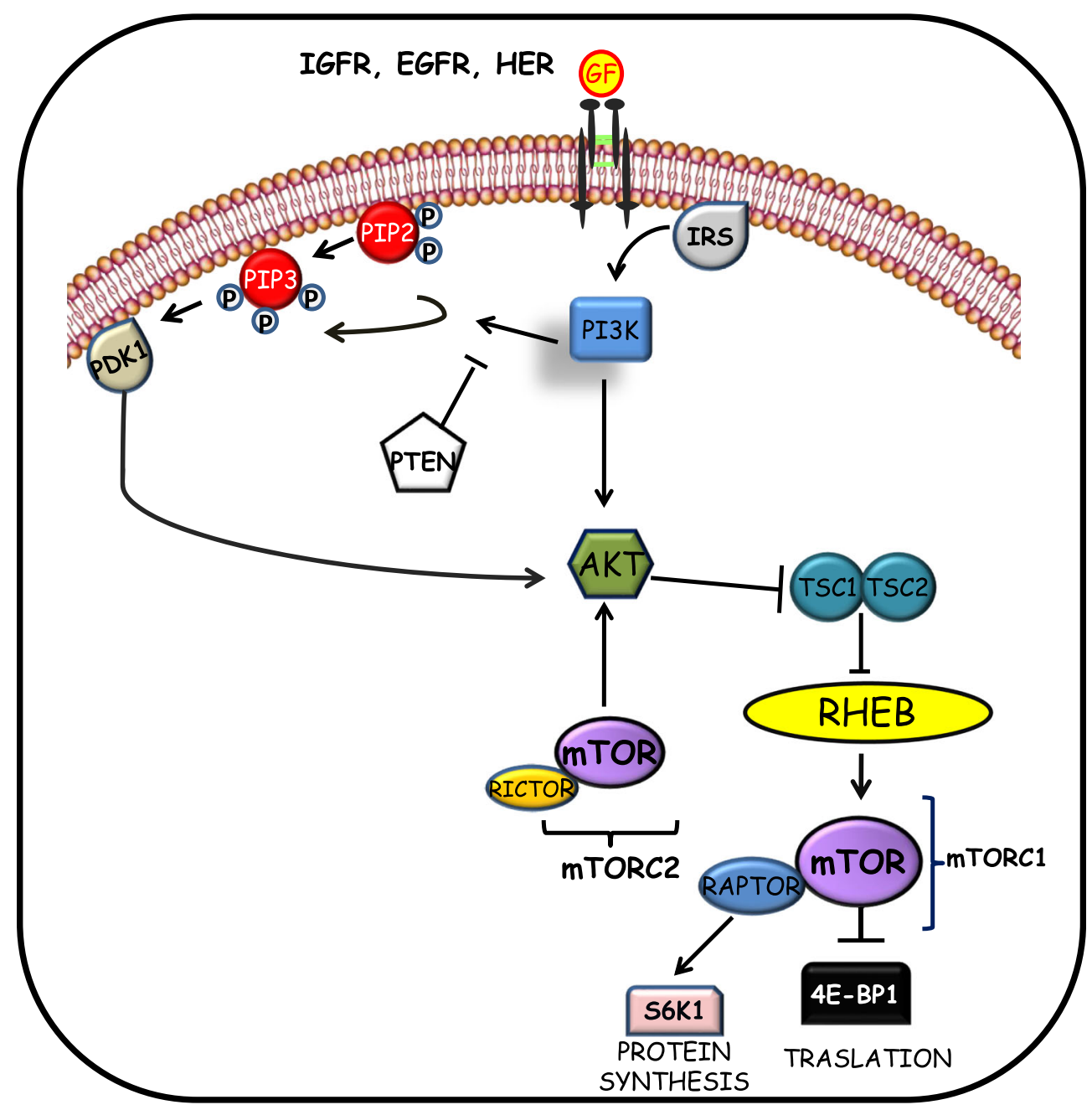


modulate the activity of the PI3K in the signaling pathway regulating cell growth, motility, and other important cellular functions [36, 37].

Also, PTEN and AKT are frequently altered in breast cancer. As widely highlighted in many forms of infiltrating breast cancers, PTEN genetic alteration and in particular its loss of expression yield a probability of incidence quantified in 4$35 \%$, while mutations or variations in AKT expression levels give a percentage of 6 and $15-41 \%$, respectively. Taken together, these genetic aberrations seem to play a pivotal role in the deregulation of PI3K/AKT pathway, and consequently, this possibly leads to disease progression and therapy resistance [38].

Other relevant mutations in breast carcinogenesis are those in TP53 gene. Indeed, $83 \%$ of basal-like tumors showed TP53 mutations compared to $15 \%$ in the luminal, normal-like, and HER2-positive tumors [39]. TP53 is a tumor suppressor gene encoding a 393 amino-acid nuclear phospho-protein whose role is to arrest propagation of genetically aberrant cells [40]. TP53 mutations also seem to play a role in the epithelialmesenchymal transition (EMT) through the inhibition of epithelial markers such as E-cadherin and the transcriptional activation of genes associated with a mesenchymal phenotype such as Twist, ZEB-1, and ZEB-2 [41]. These molecular events encourage cells to acquire a cancer stem cell-like phenotype and to promote tumor growth and metastatic spread. TP53 expression is also tightly correlated with Ki67 expression and is negatively associated with histological grade, tumor size, and co-expression of vascular endothelial growth factor (VEGF), epidermal growth factor receptor (EGFR), and type II topoisomerase (TOPO II). In addition to the aforementioned genetic alterations, also point mutations, as well as gene amplification in the ESR1 gene, even though at a lowfrequency, seem to play a role in metastatic breast cancer [32, 42]. Some of these identified mutations seem to lead to ER $\alpha$ transcriptional activity in a hormone-free manner, promoting resistance to hormonal treatments $[43,44]$.

\section{Liquid biopsy}

Diagnosis and metastasis monitoring is mostly carried out through tissue biopsy and re-biopsy, a very invasive technique, limited, and not easily acceptable by the patients.

In order to obtain an efficient and painless management of the disease over time, liquid biopsies may represent a precious basin of "new generation" biomarkers. These biomarkers are released into the bloodstream from both primary and metastatic sites, and thus, they can provide intriguing information on tumor evolution. Indeed, elevated concentrations of circulating nucleic acids have been found in blood plasma or serum of patients with various tumor types and were often associated with unfavorable outcome in some clinical studies. These findings could improve the actual approach to breast cancer patients and might in the near future help clinicians in modifying the treatment choices according to the tumor evolution.

\section{Circulating tumor DNA: a general overview}

Cell-free DNA (cfDNA) was firstly reported in 1948 by Mandel and Metais in the blood of healthy individuals [45]. Cell-free DNA is a double-stranded nucleic acid with low molecular weight than genomic DNA that circulate in the bloodstream in short (between 70 and 200 base pairs in length) or long fragments up to $21 \mathrm{~kb}$. To date, the source of cfDNA is still not completely understood, while a big contribute seems to derive essentially from nucleated blood cells. In cancer patients, a considerable proportion of cfDNA is thought to origin from tumor cells although a proportion of fragments is represented by wild-type DNA as well as in the plasma of healthy controls. Given that somatic mutation occurs exclusively in tumor cells, the identification of a mutation in cfDNA can define the portion of circulating tumor DNA (ctDNA) [46]. The possible reason for the high presence of nucleic acids into the blood of cancer patients could be explained as a part of the cell death process (apoptosis and necrosis) in cancer cells. Within the physiological clearance process of an apoptotic and/or necrotic cell, macrophages take a pivotal role in engulfing dead cells and in realizing the digested DNA into the tissue environment [47]. Another hypothesis is that ctDNA arises from the lysis of circulating cancer cells or micro metastases, already into the bloodstream, shed by tumor. The amount of ctDNA that derives from tumor cells is also affected by specific tumor characteristics, i.e., the size and the stage of the tumor as well as all the physiological filtering events triggered into the blood and lymphatic circulation [48].

Circulating tumor DNA levels are considerably lower in earlier stage disease and consequently more difficult to detect than in advanced or metastatic disease [49].

Targeted therapies have deeply changed the approaches to treatment of cancer over the past 10 years. Indeed, almost all tumors acquire resistance to systemic treatment as a result of clonal evolution and selection of resistant cells within the tumor mass. This "clonal process" is tightly dependent from the heterogeneous characteristic of a tumor. Although genotyping is the most reliable method applied for classifying tumors for future clinical decisions, tumor tissues provide only a snapshot and are often difficult to obtain. Therefore, methods are needed for a rapid, cost-effective (less-expensive) and noninvasive identification of biomarkers at various time points during the course of disease. Since ctDNA is a potential surrogate for the entire tumor genome, the use of ctDNA as a liquid biopsy may represent a valuable tool for obtaining the genetic follow-up data that are urgently needed. 
Some quantitative study reported differences in terms of circulating DNA amount between breast cancer and healthy individuals [50]. Furthermore, the levels of ctDNA in cancer patients would represent a stable parameter whose fluctuations during the course of the disease may be correlated with clinical outcome. Indeed, it has been demonstrated that high levels of ctDNA correlate with tumor size, lymph node involvement, histopathological grade, and clinical staging [51].

The presence of specific mutations helps to differentiate ctDNA from normal cfDNA. These somatic mutations, commonly single base pair substitutions, are present only in the genomes of cancer cells and are never present in normal cell DNA within the same individual. These features confer elevated specific properties to ctDNA as a biomarker. One of the most common somatic alterations in breast cancer are the mutation in PI3K gene that occurs in $40 \%$ of all breast cancers. This high mutational frequency renders PI3K a highly interesting circulating biomarker. In a recent study [52], the PI3K mutations were detected in ctDNA of 13/46 (28 \%) patients with metastatic breast cancer, but no trace of the mutation was found in patients with resectable breast cancer. These results suggested that the detection of ctDNA mutations is lower in the early stage disease compared to more advanced stage and demonstrated the feasibility of detection of PI3K mutation in plasma [53].

A more recent study highlighted the utility of ctDNA in the clinical management of breast cancer patients. The study of Dawson et al., conducted on 30 women with metastatic disease under chemotherapy, compared the radiographic measurement of tumors with the molecular analysis of ctDNA as well as CA $15-3$ and circulating tumor cells. With respect to CA15-3 and CTCs which showed not high detectability within the sample, ctDNA was identified in almost all 30 patients (29/30) in whom mutations of TP53 and PI3K were already characterized in tumor biopsy specimens. This assay proved the high sensitivity of ctDNA for detecting presence of metastatic disease and study tumor burden when compared to the aforementioned biomarkers. Furthermore, the researchers found that ctDNA levels are often associated with both treatment efficacy and survival. In fact, patient with longer survival showed lower ctDNA levels if compared with patients who showed early disease progression and shorter survival [54, 55].

\section{Technical approaches for ctDNA}

Nowadays, circulating tumor DNA represent a very high challenging and innovative analyte. Because of its very low concentration and degree of fragmentation in liquid samples, it needs very sensitive detection methods. Moreover, it has been demonstrated that plasma represents a better ctDNA source than serum, although the amount of ctDNA in serum can be 2-24 times higher than in plasma [56]. Indeed, during the
ctDNA isolation process, it exists a high risk of cell contamination, and for this reason, it has been recommended the use of plasma as a source for the analysis of tumor-specific DNA. Moreover, another benefit deriving from plasma ctDNA is the lower concentration of background wild-type DNA [57]. One of the main issues in ctDNA analysis is the assay specificity and sensitivity. In fact, a major drawback of the ctDNA assays is the low frequency of some mutations that occur in tumors and the risk of interference by wild-type sequences [58]. There are now many methods for assessing ctDNA including the following:

- BEAMing a technology which combines emulsion PCR with magnetic beads and flow cytometry for the highly sensitive detection and quantification of tumor DNA molecules

- Next-generation sequencing approaches

- Digital PCR platforms

Each technique is able to detect mutant alleles with a sensitivity of at least $2 \%$. Unfortunately, costs and feasibility of developing the aforementioned methods in the clinic practice show several technical issues. However, the use of these strategies would allow and help clinicians in monitoring the disease progression by quantifying the number of ctDNA copies per milliliter of plasma (copies $/ \mathrm{mL}$ ) [59].

\section{Circulating tumor DNA: applications}

The application of new sensitive methods for very rare circulating mutation is urgently needed. In fact, the feasibility and potential utility of ctDNA for detection of PI3K mutations have been already deeply highlighted in patients with metastatic breast cancer $[53,60]$.

Recently, the detection of tumor DNA from tissue specimens and paired plasma samples has been reported. Moreover, the possibility to find mutations in ctDNA at early stage breast cancer can acquire high value as a marker for "minimal residual disease" (MRD) in those patients subjected to curative surgery. In particular, a recent work published by the group of Beaver et al. [61] investigated PI3K exon 20 and exon 9 mutational status through droplet digital PCR (ddPCR) in both tissue and paired plasma samples. The ddPCR is a new, highly sensitive, and cost-effective method that allows the analysis of rare mutation in a background of thousands of wild-type molecules. The aim of this study was to provide a proof-of-concept on the potential role of ctDNA as a marker for MRD. Nowadays, breast surgery represents the elective treatment for localized breast cancer patients. Unfortunately, to date, we do not have any marker to recognize patients definitively cured from those who may still have residual disease and thus may benefit from adjuvant treatment [46]. Beaver et al. [61] have analyzed 29 presurgery plasma 
samples and compared the results obtained with paired postsurgery samples with the aim to highlight differences in PI3K fraction abundance among samples before and after resection. They showed that PI3K (exons 9 and 20) mutation levels in plasma differ among pre- and post-surgery withdrawal. These results, although preliminary, are very intriguing and could lead to a more personalized breast cancer management [61].

The feasibility of ctDNA analysis have been, not so far, investigated by Higgins et al., by using a BEAMing approach. This analysis was conducted within a double, retrospective and prospective, cohort of metastatic breast cancer patients. In the retrospective study, the aim was to verify BEAMing feasibility for the detection of PI3KCA mutations in plasma that was present in paired tumor tissue specimens. The method resulted reliable in identifying the same mutations observed in FFPE-derived tissue samples with a concordance of $100 \%$. In the prospective analysis, a cohort of 51 metastatic breast cancers was studied for PIK3CA mutations both by sequencing and BEAMing in tumor tissue and paired ctDNA. Also for this cohort, a high concordance rate was highlighted [62].

Another interesting molecular marker is TP53 mutation that can be evaluated from ctDNA as well as PI3K mutations. In particular, Madic et al. have demonstrated that TP53 mutations in plasma may help in the management of triple-negative breast cancer patients [63]. Mutations within TP53 sequence were analyzed by using next-generation sequencing platforms. TAm-Seq-based Illumina and 454 sequencing successfully allowed TP53 mutation detection in $84 \%$ of tumor tissue specimens. The double NGS approach confirmed the same genetic alteration also in the paired plasma in $81 \%$ of cases, demonstrating the robustness of NGS as a method to detect TP53 mutations [63].

\section{CTCs: a general overview}

Circulating tumor cells (CTCs) were first observed in the nineteenth century $[64,65]$. Generally, CTCs have peculiar features including a visible nucleus and cytoplasm, and are mainly characterized for the expression of cytokeratin and no CD45 expression [66].

Since CTCs do not circulate in healthy patients and have been detected in patients with almost all cancer types, they acquire high relevance for studying the biology of the early metastatic disease and for diagnosis of metastatic patients [67].

Circulating tumor cells show a very low frequency in bloodstream [68]. Indeed, the number of CTCs would provide real-time information on the clinical behavior of many tumors, and they could additionally predict clinical outcome in metastatic patients $[69,70]$ as they seem to play a crucial role in mediating metastatic spread [71].
In fact, metastasis is a multistep process starting with the detachment of high malignant potential cells from the primary tumor site that could flow in bloodstream or the lymphatic system, and reach new distant sites. The final step for a circulating tumor cell is to extravasate, implant, and then proliferate generating a macroscopic, clinically detectable neoplastic growths [72].

Since CTCs seem to play crucial roles not only in metastasis but also in resistance to drug administration, it is fundamental to understand their clinical role during the early stages of the disease $[73,74]$.

Indeed, CTCs can predict early recurrence as well as decreased overall survival in chemo-naive patients with nonmetastatic breast cancer. These results confirm that the assessment of CTC might provide important prognostic information in these patients [75].

In a work by Franken et al. [76], a correlation study between stage and CTCs number was reported. The CTCs number evaluation was carried out using three cohorts of patients in stages I, II, and III, respectively. The detection of $\geq 1$ CTCs in bloodstream was $16 \%$ for breast cancer patients at stage I, $18 \%$ for stage II, and $31 \%$ for stage III. Therefore, CTC number positively correlates to disease stage, and patients with at least one CTC detected showed higher risk of recurrence than patients with no CTC detected. Furthermore, CTC evaluation before surgery plays a pivotal role in predicting disease-free survival (DFS) [76].

Furthermore, a massive presence correlates more strongly with poor prognosis than single CTCs in metastatic breast cancer patients [77]. On the basis of the different degree of epithelial and/or mesenchymal marker expression, CTCs can be divided different subpopulations $[78,79]$. These subpopulations may also acquire general cancer stem-like properties allowing them to act as not differentiated cells by regulating several biological processes as quiescence, self-renewal, asymmetric division, drug resistance, resistance to radiation, and abilities in surviving within a foreign microenvironment, resulting then in metastasis. In fact, these stem-like breast cells commonly show a CD44+/CD24- phenotype [80] or the expression of aldehyde dehydrogenase 1 (ALDH1) [81].

\section{Technical approaches for CTCs}

CTCs are high malignant cells that circulate in bloodstream at extremely low frequency. CTC number is even lower in nonmetastatic disease [82, 83]. Current technical approaches for detecting CTCs can be mainly classified in enrichment and detection steps on the basis of specific capture properties (Fig. 2). Through enrichment methods, CTCs are detected for their physical properties such as cell size, density, and positive or negative immunoselection. In fact, CTCs are 20-30 $\mu \mathrm{m}$ in diameter, while blood cells 


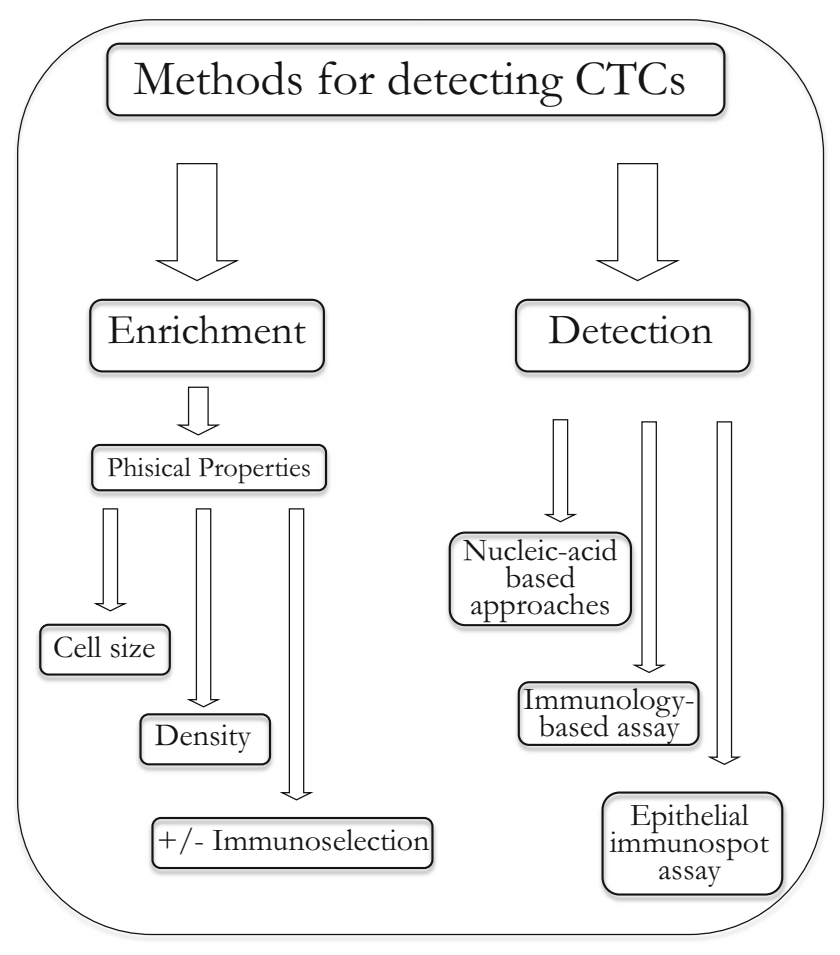

Fig. 2 Main technical approaches for CTCs isolation and enrichment

measure $8-12 \mu \mathrm{m}$ [84]. Indeed, in order to discriminate cells for their size, several filtration methods have been developed [85]. Mononuclear cells and CTCs can also be discriminated from other cells on the basis of their density by performing a ficoll-gradient enrichment [86]. However, the most commonly used techniques for CTCs enrichment are the immuno-based approaches. The only FDA- approved automatized immunomagnetic enrichment is the CellSearch system. It relies on the ability of magnetic ferrofluids coupled to anti-EpCAM antibodies to recognize and bind only epithelial tumor cells expressing EpCAM, indirectly discriminating them from blood cells. AntiEpCAM antibodies are added to $7.5 \mathrm{~mL}$ of peripheral whole blood [51]. EpCAM and members of the CKs family (CK8, CK18, and CK19) have been identified as useful markers for positive discrimination in patients with carcinoma. In particular, positive markers for breast cancer enrichment are considered EpCAM/CK, HER-2, Mammag lobin, and MUC-1 for their high expression degree in cancer cells [87]. On the contrary, negative discrimination can be carried out by using antigens as CD45, expressed in leukocytes, and CD61, expressed in megakaryocytes and platelets [88].

On the other hand, methods of CTC detection are divided into the following:

1. Nucleic-acid-based approaches: it relies on specific DNA or mRNA markers useful to identify and discriminate
CTCs as epithelial-specific genes ( $C K$ and $E p C A M)$, organ-specific markers (CEA, PSA [89], mammaglobin [90], and $M U C-1$ [91]) and tumor-specific markers such as the EGFR and HER-2 genes which are normally absent in circulation [92].

2. Immunology-based assay: it represents an effective method for CTCs detection and isolation. It uses labeled antibodies against epithelial or tumor-associated antigens along with automated digital microscopy or flow cytometry to identify and quantify CTCs.

3. Epithelial immunospot (EPISPOT) assay: it allows the detection of tumor-specific proteins.

\section{Circulating tumor cells: applications}

CTCs represent a reliable therapeutic indicator for many forms of cancer as indicated in recent evidences that suggested a strong correlation between CTC number and outcome with respect to PFS and OS [93, 94]. Many clinical trials have been specifically drawn to demonstrate that CTC identification and characterization may be used for improving the management of breast cancer patients as well for patients' stratification. Indeed, metastatic breast cancer patients showing a $\geq 5$ CTCs number after 3 5 weeks from systemic and hormone- therapies correlate with shorter PFS than patients with less than five CTCs. Moreover, this strong correlation has been also demonstrated between CTCs counts and radiographic disease progression in patients treated with chemotherapies and hormone therapies [95]. Therefore, CTC isolation could be used in addition to standard methods for monitoring disease status in metastatic breast cancer [96]. A few studies suggest that CTC number may have a potential prognostic role in early-stage patients. Indeed, CTCs are detectable in $20-40 \%$ of patients with early-stage breast cancer according to the aforementioned PCR-based assays and almost $10 \%$ of early-stage patients according to the CellSearch system [93, 94, 97]. With respect to the main genetic alteration involved in breast carcinogenesis, Fernandez et al. [98] showed the feasibility of using CTCs for TP53 mutation detection as a noninvasive method. In particular, CTCs from two triple negative breast cancer patients were enriched using CellSearch system and single cell selected by DEPArray ${ }^{\mathrm{TM}}$. Distinct CTC populations were found, some of which harboring the same TP53 mutation (R110 delG), and also confirmed in the paired tumor samples, while some other showed either a different TP53 mutation (TP53 R110 delC) or the wildtype allele. These results indicate that CTCs could represent a noninvasive source of cancer cells for the determination of disease progression and the identification of new potential therapeutic targets [98]. 


\section{Conclusions}

In the last few years, we have experienced an increased interest of genetic aberration role in carcinogenesis. In fact, the use of molecular biomarkers in the next future would probably help clinicians in evolving their actual approach to patients' management for different forms of cancer (i.e., $c-K I T$ and PDGFRA in GIST, EGFR in lung cancer, $B R A F$ in melanoma, $R A S$ in colorectal cancer, PTEN and TP53 in breast cancer). Moreover, the introduction in clinical practice of many new generation approaches is day-by-day increasing the spectrum of gene mutations whose involvement in cancer would drive oncologist to new personalized treatments delivering. Despite this wide range of new acquired knowledge, mortality rate is still high. This is mainly caused by the development of metastasis due to cancer cell detachment from the primary tumors. It is now widely demonstrated that metastasis and primary tumors are biologically different. Therefore, these heterogeneity characteristics give to the metastatic disease the reason for considering it as a world apart to be still completely discovered. Thus, characterizing new lesions through a re-biopsy appears to be fundamental. Unfortunately, re-biopsy is not always indicated due to many reasons, first of all the extreme invasiveness that limits the procedure only to certain locations. In order to overcome these issues, the possibility of using liquid biopsies plays a primary role. CTCs and ctDNA have been well characterized as useful new and noninvasive biomarkers that can be used routinely because of their ease of access within many body fluids. Circulating tumor DNA is a double-stranded nucleic acid with low molecular weight that has been detected in the plasma and serum of cancer patients as well as in that of healthy controls. In cancer patients a considerable proportion of plasma DNA seems to originate from tumor cells, although another amount seem to derive from circulating cancer cells lysis as well as micro metastases. Moreover, ctDNA amount strongly correlates with tumor stage and size. The use of ctDNA as a liquid biopsy may help to obtain the genetic follow-up data that are urgently needed. Regarding CTCs analysis, at present, their role can be mainly limited to prognostic purposes, but there is an increasing interest in the development of new techniques for their molecular characterization. CTCs are cells that escape from the primary tumors and migrate through the circulation until they colonize a new district. It is wellknown from recent clinical studies that their count is proportional to a poorer prognosis in various tumor types. Following this consideration, the growing interest in the last few years by the scientific community to liquid biopsies gives hope for their routinely application in clinic practice. Even if the road seems to be long and winding, new efforts and investments are needed to bridge the gap still existing.

Compliance with ethical guidelines

Conflicts of interest None

\section{References}

1. Bombonati A, Sgroi DC. The molecular pathology of breast cancer progression. J Pathol. 2011;223(2):307-17.

2. Siegel RL, Miller KD, Jemal A. Cancer statistics, 2015. CA Cancer J Clin. 2015;65(1):5-29.

3. Fanale D, Amodeo V, Corsini LR, Rizzo S, Bazan V, Russo A. Breast cancer genome-wide association studies: there is strength in numbers. Oncogene. 2012;31(17):2121-8.

4. Russo A, Calo V, Bruno L, Schiro V, Agnese V, Cascio S, et al. Is BRCA1-5083del19, identified in breast cancer patients of Sicilian origin, a Calabrian founder mutation? Breast Cancer Res Treat. 2009;113(1):67-70.

5. Fanale D, Bazan V, Caruso S, Castiglia M, Bronte G, Rolfo C, et al. Hypoxia and human genome stability: downregulation of BRCA2 expression in breast cancer cell lines. Biomed Res Int. 2013;2013: 746858.

6. Ottini L, Capalbo C, Rizzolo P, Silvestri V, Bronte G, Rizzo S, et al. HER2-positive male breast cancer: an update. Breast Cancer (Dove Med Press). 2010;2:45-58.

7. Fanale D, Bazan V, Corsini LR, Caruso S, Insalaco L, Castiglia M, et al. HIF-1 is involved in the negative regulation of AURKA expression in breast cancer cell lines under hypoxic conditions. Breast Cancer Res Treat. 2013;140(3):505-17.

8. Sorlie T, Perou CM, Tibshirani R, Aas T, Geisler S, Johnsen H, et al. Gene expression patterns of breast carcinomas distinguish tumor subclasses with clinical implications. Proc Natl Acad Sci U S A. 2001;98(19):10869-74.

9. Senkus E, Kyriakides S, Ohno S, Penault-Llorca F, Poortmans P, Rutgers E, et al. Primary breast cancer: ESMO Clinical Practice Guidelines for diagnosis, treatment and follow-up. Ann Oncol. 2015;26 Suppl 5:v8-30.

10. Curtis C, Shah SP, Chin SF, Turashvili G, Rueda OM, Dunning MJ, et al. The genomic and transcriptomic architecture of 2,000 breast tumours reveals novel subgroups. Nature. 2012;486(7403):346-52.

11. Yadav BS, Chanana P, Jhamb S. Biomarkers in triple negative breast cancer: a review. World J Clin Oncol. 2015;6(6):252-63.

12. Hurvitz S, Mead M. Triple-negative breast cancer: advancements in characterization and treatment approach. Curr Opin Obstet Gynecol. 2016;28(1):59-69.

13. Nik-Zainal S, Van Loo P, Wedge DC, Alexandrov LB, Greenman $\mathrm{CD}$, Lau KW, et al. The life history of 21 breast cancers. Cell. 2012;149(5):994-1007.

14. Aguirre-Ghiso JA. Models, mechanisms and clinical evidence for cancer dormancy. Nat Rev Cancer. 2007;7(11):834-46.

15. Klein CA. Parallel progression of primary tumours and metastases. Nat Rev Cancer. 2009;9(4):302-12.

16. Sadovska L, Eglitis J, Line A. Extracellular Vesicles as Biomarkers and Therapeutic Targets in Breast Cancer. Anticancer Res. 2015;35(12):6379-90.

17. Yu DD, Wu Y, Shen HY, Lv MM, Chen WX, Zhang XH, et al. Exosomes in development, metastasis and drug resistance of breast cancer. Cancer Sci. 2015;106(8):959-64. 
18. Green TM, Alpaugh ML, Barsky SH, Rappa G, Lorico A. Breast cancer-derived extracellular vesicles: characterization and contribution to the metastatic phenotype. Biomed Res Int. 2015;2015: 634865.

19. Corsini LR, Bronte G, Terrasi M, Amodeo V, Fanale D, Fiorentino $\mathrm{E}$, et al. The role of microRNAs in cancer: diagnostic and prognostic biomarkers and targets of therapies. Expert Opin Ther Targets. 2012;16 Suppl 2:S103-109.

20. Franchina T, Amodeo V, Bronte G, Savio G, Ricciardi GR, Picciotto M, et al. Circulating miR-22, miR-24 and miR-34a as novel predictive biomarkers to pemetrexed-based chemotherapy in advanced non-small cell lung cancer. J Cell Physiol. 2014;229(1):97-9.

21. Amodeo V, Bazan V, Fanale D, Insalaco L, Caruso S, Cicero G, et al. Effects of anti-miR-182 on TSP-1 expression in human colon cancer cells: there is a sense in antisense? Expert Opin Ther Targets. 2013;17(11):1249-61.

22. Bronte F, Bronte G, Fanale D, Caruso S, Bronte E, Bavetta MG, et al. HepatomiRNoma: the proposal of a new network of targets for diagnosis, prognosis and therapy in hepatocellular carcinoma. Crit Rev Oncol Hematol. 2016;97:312-21.

23. Stratton MR, Campbell PJ, Futreal PA. The cancer genome. Nature. 2009;458(7239):719-24.

24. D'Anneo A, Carlisi D, Emanuele S, Buttitta G, Di Fiore R, Vento R, et al. Parthenolide induces superoxide anion production by stimulating EGF receptor in MDA-MB-231 breast cancer cells. Int $\mathbf{J}$ Oncol. 2013;43(6):1895-900.

25. Sanchez CG, Ma CX, Crowder RJ, Guintoli T, Phommaly C, Gao F, et al. Preclinical modeling of combined phosphatidylinositol-3kinase inhibition with endocrine therapy for estrogen receptorpositive breast cancer. Breast Cancer Res. 2011;13(2):R21.

26. Di Fiore R, Drago-Ferrante R, D'Anneo A, Augello G, Carlisi D, De Blasio A, et al. In human retinoblastoma Y79 cells okadaic acidparthenolide co-treatment induces synergistic apoptotic effects, with PTEN as a key player. Cancer Biol Ther. 2013;14(10):922-31.

27. Engelman JA, Luo J, Cantley LC. The evolution of phosphatidylinositol 3-kinases as regulators of growth and metabolism. Nat Rev Genet. 2006;7(8):606-19.

28. Franke TF, Hornik CP, Segev L, Shostak GA, Sugimoto C. PI3K/ Akt and apoptosis: size matters. Oncogene. 2003;22(56):8983-98.

29. Fingar DC, Salama S, Tsou C, Harlow E, Blenis J. Mammalian cell size is controlled by mTOR and its downstream targets S6K1 and 4EBP1/eIF4E. Genes Dev. 2002;16(12):1472-87.

30. Kim DH, Sarbassov DD, Ali SM, King JE, Latek RR, ErdjumentBromage $\mathrm{H}$, et al. mTOR interacts with raptor to form a nutrientsensitive complex that signals to the cell growth machinery. Cell. 2002;110(2):163-75.

31. Kim DH, Sarbassov DD, Ali SM, Latek RR, Guntur KV, ErdjumentBromage $\mathrm{H}$, et al. GbetaL, a positive regulator of the rapamycinsensitive pathway required for the nutrient-sensitive interaction between raptor and mTOR. Mol Cell. 2003;11(4):895-904.

32. Cancer Genome Atlas Network. Comprehensive molecular portraits of human breast tumours. Nature. 2012;490(7418):61-70.

33. Bellacosa A, Kumar CC, Di Cristofano A, Testa JR. Activation of AKT kinases in cancer: implications for therapeutic targeting. Adv Cancer Res. 2005;94:29-86.

34. Vivanco I, Sawyers CL. The phosphatidylinositol 3-Kinase AKT pathway in human cancer. Nat Rev Cancer. 2002;2(7):489-501.

35. Campbell IG, Russell SE, Choong DY, Montgomery KG, Ciavarella ML, Hooi CS, et al. Mutation of the PIK3CA gene in ovarian and breast cancer. Cancer Res. 2004;64(21):7678-81.

36. Oshiro C, Kagara N, Naoi Y, Shimoda M, Shimomura A, Maruyama N, et al. PIK3CA mutations in serum DNA are predictive of recurrence in primary breast cancer patients. Breast Cancer Res Treat. 2015;150(2):299-307.
37. Samuels Y, Diaz Jr LA, Schmidt-Kittler O, Cummins JM, Delong L, Cheong I, et al. Mutant PIK3CA promotes cell growth and invasion of human cancer cells. Cancer Cell. 2005;7(6):561-73.

38. Cuorvo LV, Verderio P, Ciniselli CM, Girlando S, Decarli N, Leonardi E, et al. PI3KCA mutation status is of limited prognostic relevance in ER-positive breast cancer patients treated with hormone therapy. Virchows Arch. 2014;464(1):85-93.

39. Langerod A, Zhao H, Borgan O, Nesland JM, Bukholm IR, Ikdahl $\mathrm{T}$, et al. TP53 mutation status and gene expression profiles are powerful prognostic markers of breast cancer. Breast Cancer Res. 2007;9(3):R30.

40. Nakopoulou LL, Alexiadou A, Theodoropoulos GE, Lazaris AC, Tzonou A, Keramopoulos A. Prognostic significance of the coexpression of $\mathrm{p} 53$ and c-erbB-2 proteins in breast cancer. J Pathol. 1996;179(1):31-8.

41. Kogan-Sakin I, Tabach Y, Buganim Y, Molchadsky A, Solomon H, Madar S, et al. Mutant p53(R175H) upregulates Twist1 expression and promotes epithelial-mesenchymal transition in immortalized prostate cells. Cell Death Differ. 2011;18(2):271-81.

42. Reis-Filho JS, Drury S, Lambros MB, Marchio C, Johnson N, Natrajan R, et al. ESR1 gene amplification in breast cancer: a common phenomenon? Nat Genet. 2008;40(7):809-10. author reply 810-802.

43. Jeselsohn R, Yelensky R, Buchwalter G, Frampton G, MericBernstam F, Gonzalez-Angulo AM, et al. Emergence of constitutively active estrogen receptor-alpha mutations in pretreated advanced estrogen receptor-positive breast cancer. Clin Cancer Res. 2014;20(7):1757-67.

44. Toy W, Shen Y, Won H, Green B, Sakr RA, Will M, et al. ESR1 ligand-binding domain mutations in hormone-resistant breast cancer. Nat Genet. 2013;45(12):1439-45.

45. Sausen M, Parpart S, Diaz Jr LA. Circulating tumor DNA moves further into the spotlight. Genome Med. 2014;6(5):35.

46. Diaz Jr LA, Bardelli A. Liquid biopsies: genotyping circulating tumor DNA. J Clin Oncol. 2014;32(6):579-86.

47. Stroun M, Maurice P, Vasioukhin V, Lyautey J, Lederrey C, Lefort F, et al. The origin and mechanism of circulating DNA. Ann N Y Acad Sci. 2000;906:161-8.

48. Schwarzenbach H, Hoon DS, Pantel K. Cell-free nucleic acids as biomarkers in cancer patients. Nat Rev Cancer. 2011;11(6):426-37.

49. Olsson E, Winter C, George A, Chen Y, Howlin J, Tang MH, et al. Serial monitoring of circulating tumor DNA in patients with primary breast cancer for detection of occult metastatic disease. EMBO Mol Med. 2015;7(8):1034-47.

50. Kohler C, Radpour R, Barekati Z, Asadollahi R, Bitzer J, Wight E, et al. Levels of plasma circulating cell free nuclear and mitochondrial DNA as potential biomarkers for breast tumors. Mol Cancer. 2009;8:105.

51. Catarino R, Ferreira MM, Rodrigues H, Coelho A, Nogal A, Sousa A, et al. Quantification of free circulating tumor DNA as a diagnostic marker for breast cancer. DNA Cell Biol. 2008;27(8):415-21.

52. Sorenson GD, Pribish DM, Valone FH, Memoli VA, Bzik DJ, Yao SL. Soluble normal and mutated DNA sequences from single-copy genes in human blood. Cancer Epidemiol Biomarkers Prev. 1994;3(1):67-71.

53. Board RE, Wardley AM, Dixon JM, Armstrong AC, Howell S, Renshaw L, et al. Detection of PIK3CA mutations in circulating free DNA in patients with breast cancer. Breast Cancer Res Treat. 2010;120(2):461-7.

54. Dawson SJ, Tsui DW, Murtaza M, Biggs H, Rueda OM, Chin SF, et al. Analysis of circulating tumor DNA to monitor metastatic breast cancer. N Engl J Med. 2013;368(13):1199-209.

55. Esposito A, Bardelli A, Criscitiello C, Colombo N, Gelao L, Fumagalli L, et al. Monitoring tumor-derived cell-free DNA in patients with solid tumors: clinical perspectives and research opportunities. Cancer Treat Rev. 2014;40(5):648-55. 
56. Jung M, Klotzek S, Lewandowski M, Fleischhacker M, Jung K. Changes in concentration of DNA in serum and plasma during storage of blood samples. Clin Chem. 2003;49(6 Pt 1):1028-9.

57. Umetani N, Kim J, Hiramatsu S, Reber HA, Hines OJ, Bilchik AJ, et al. Increased integrity of free circulating DNA in sera of patients with colorectal or periampullary cancer: direct quantitative PCR for ALU repeats. Clin Chem. 2006;52(6):1062-9.

58. Heitzer E, Ulz P, Geigl JB. Circulating tumor DNA as a liquid biopsy for cancer. Clin Chem. 2015;61(1):112-23.

59. Crowley E, Di Nicolantonio F, Loupakis F, Bardelli A. Liquid biopsy: monitoring cancer-genetics in the blood. Nat Rev Clin Oncol. 2013;10(8):472-84.

60. Schwarzenbach $\mathrm{H}$. Circulating nucleic acids as biomarkers in breast cancer. Breast Cancer Res. 2013;15(5):211.

61. Beaver JA, Jelovac D, Balukrishna S, Cochran RL, Croessmann S, Zabransky DJ, et al. Detection of cancer DNA in plasma of patients with early-stage breast cancer. Clin Cancer Res. 2014;20(10):264350 .

62. Higgins MJ, Jelovac D, Barnathan E, Blair B, Slater S, Powers P, et al. Detection of tumor PIK3CA status in metastatic breast cancer using peripheral blood. Clin Cancer Res. 2012;18(12):3462-9.

63. Madic J, Kiialainen A, Bidard FC, Birzele F, Ramey G, Leroy Q, et al. Circulating tumor DNA and circulating tumor cells in metastatic triple negative breast cancer patients. Int J Cancer. 2015;136(9): $2158-65$

64. Rolfo C, Castiglia M, Hong D, Alessandro R, Mertens I, Baggerman G, et al. Liquid biopsies in lung cancer: the new ambrosia of researchers. Biochim Biophys Acta. 2014;1846(2):53946.

65. Krebs MG, Hou JM, Ward TH, Blackhall FH, Dive C. Circulating tumour cells: their utility in cancer management and predicting outcomes. Ther Adv Med Oncol. 2010;2(6):351-65.

66. Allard WJ, Matera J, Miller MC, Repollet M, Connelly MC, Rao C, et al. Tumor cells circulate in the peripheral blood of all major carcinomas but not in healthy subjects or patients with nonmalignant diseases. Clin Cancer Res. 2004;10(20):6897-904.

67. Pantel K, Brakenhoff RH, Brandt B. Detection, clinical relevance and specific biological properties of disseminating tumour cells. Nat Rev Cancer. 2008;8(5):329-40.

68. Sun YF, Yang XR, Zhou J, Qiu SJ, Fan J, Xu Y. Circulating tumor cells: advances in detection methods, biological issues, and clinical relevance. J Cancer Res Clin Oncol. 2011;137(8):1151-73.

69. Cristofanilli M, Budd GT, Ellis MJ, Stopeck A, Matera J, Miller $\mathrm{MC}$, et al. Circulating tumor cells, disease progression, and survival in metastatic breast cancer. N Engl J Med. 2004;351(8):781-91.

70. Cohen SJ, Punt CJ, Iannotti N, Saidman BH, Sabbath KD, Gabrail NY, et al. Relationship of circulating tumor cells to tumor response, progression-free survival, and overall survival in patients with metastatic colorectal cancer. J Clin Oncol. 2008;26(19):3213-21.

71. Pantel K, Alix-Panabieres C, Riethdorf S. Cancer micrometastases. Nat Rev Clin Oncol. 2009;6(6):339-51.

72. Valastyan S, Weinberg RA. Tumor metastasis: molecular insights and evolving paradigms. Cell. 2011;147(2):275-92.

73. Cortesi E, Palleschi M, Magri V, Naso G. The promise of liquid biopsy in cancer: a clinical perspective. Chin J Cancer Res. 2015;27(5):488-90.

74. Lianidou ES, Markou A, Strati A. The Role of CTCs as Tumor Biomarkers. Adv Exp Med Biol. 2015;867:341-67.

75. Lucci A, Hall CS, Lodhi AK, Bhattacharyya A, Anderson AE, Xiao $\mathrm{L}$, et al. Circulating tumour cells in non-metastatic breast cancer: a prospective study. Lancet Oncol. 2012;13(7):688-95.

76. Franken B, de Groot MR, Mastboom WJ, Vermes I, van der Palen J, Tibbe AG, et al. Circulating tumor cells, disease recurrence and survival in newly diagnosed breast cancer. Breast Cancer Res. 2012;14(5):R133.
77. Aceto N, Bardia A, Miyamoto DT, Donaldson MC, Wittner BS, Spencer JA, et al. Circulating tumor cell clusters are oligoclonal precursors of breast cancer metastasis. Cell. 2014;158(5):1110-22.

78. Yu M, Bardia A, Wittner BS, Stott SL, Smas ME, Ting DT, et al. Circulating breast tumor cells exhibit dynamic changes in epithelial and mesenchymal composition. Science. 2013;339(6119):580-4.

79. Armstrong AJ, Marengo MS, Oltean S, Kemeny G, Bitting RL, Turnbull JD, et al. Circulating tumor cells from patients with advanced prostate and breast cancer display both epithelial and mesenchymal markers. Mol Cancer Res. 2011;9(8):997-1007.

80. Al-Hajj M, Wicha MS, Benito-Hernandez A, Morrison SJ, Clarke MF. Prospective identification of tumorigenic breast cancer cells. Proc Natl Acad Sci U S A. 2003;100(7):3983-8.

81. Ginestier C, Hur MH, Charafe-Jauffret E, Monville F, Dutcher J, Brown M, et al. ALDH1 is a marker of normal and malignant human mammary stem cells and a predictor of poor clinical outcome. Cell Stem Cell. 2007;1(5):555-67.

82. Alunni-Fabbroni M, Sandri MT. Circulating tumour cells in clinical practice: methods of detection and possible characterization. Methods. 2010;50(4):289-97.

83. Tibbe AG, Miller MC, Terstappen LW. Statistical considerations for enumeration of circulating tumor cells. Cytometry A. 2007;71(3): 154-62.

84. Vona G, Sabile A, Louha M, Sitruk V, Romana S, Schutze K, et al. Isolation by size of epithelial tumor cells: a new method for the immunomorphological and molecular characterization of circulatingtumor cells. Am J Pathol. 2000;156(1):57-63.

85. Lin HK, Zheng S, Williams AJ, Balic M, Groshen S, Scher HI, et al. Portable filter-based microdevice for detection and characterization of circulating tumor cells. Clin Cancer Res. 2010;16(20):5011-8.

86. Paterlini-Brechot P, Benali NL. Circulating tumor cells (CTC) detection: clinical impact and future directions. Cancer Lett. 2007;253(2):180-204.

87. Meng S, Tripathy D, Shete S, Ashfaq R, Haley B, Perkins S, et al. HER-2 gene amplification can be acquired as breast cancer progresses. Proc Natl Acad Sci U S A. 2004;101(25):9393-8.

88. Witzig TE, Bossy B, Kimlinger T, Roche PC, Ingle JN, Grant C, et al. Detection of circulating cytokeratin-positive cells in the blood of breast cancer patients using immunomagnetic enrichment and digital microscopy. Clin Cancer Res. 2002;8(5):1085-91.

89. Mejean A, Vona G, Nalpas B, Damotte D, Brousse N, Chretien Y, et al. Detection of circulating prostate derived cells in patients with prostate adenocarcinoma is an independent risk factor for tumor recurrence. J Urol. 2000;163(6):2022-9.

90. Zach O, Kasparu H, Krieger O, Hehenwarter W, Girschikofsky M, Lutz D. Detection of circulating mammary carcinoma cells in the peripheral blood of breast cancer patients via a nested reverse transcriptase polymerase chain reaction assay for mammaglobin mRNA. J Clin Oncol. 1999;17(7):2015-9.

91. de Cremoux P, Extra JM, Denis MG, Pierga JY, Bourstyn E, Nos C, et al. Detection of MUC1-expressing mammary carcinoma cells in the peripheral blood of breast cancer patients by real-time polymerase chain reaction. Clin Cancer Res. 2000;6(8):3117-22.

92. Hauch S, Zimmermann S, Lankiewicz S, Zieglschmid V, Bocher O, Albert WH. The clinical significance of circulating tumour cells in breast cancer and colorectal cancer patients. Anticancer Res. 2007;27(3A):1337-41.

93. Stathopoulou A, Vlachonikolis I, Mavroudis D, Perraki M, Kouroussis C, Apostolaki S, et al. Molecular detection of cytokeratin-19-positive cells in the peripheral blood of patients with operable breast cancer: evaluation of their prognostic significance. J Clin Oncol. 2002;20(16):3404-12.

94. Stathopoulou A, Ntoulia M, Perraki M, Apostolaki S, Mavroudis D, Malamos N, et al. A highly specific real-time RT-PCR method for the quantitative determination of CK-19 mRNA positive cells in 
peripheral blood of patients with operable breast cancer. Int J Cancer. 2006;119(7):1654-9.

95. Bidard FC, Fehm T, Ignatiadis M, Smerage JB, Alix-Panabieres C, Janni W, et al. Clinical application of circulating tumor cells in breast cancer: overview of the current interventional trials. Cancer Metastasis Rev. 2013;32(1-2):179-88.

96. Tseng JY, Yang CY, Liang SC, Liu RS, Jiang JK, Lin CH. Dynamic changes in numbers and properties of circulating tumor cells and their potential applications. Cancers (Basel). 2014;6(4):2369-86.
97. Fehm T, Hoffmann O, Aktas B, Becker S, Solomayer EF, Wallwiener D, et al. Detection and characterization of circulating tumor cells in blood of primary breast cancer patients by RT-PCR and comparison to status of bone marrow disseminated cells. Breast Cancer Res. 2009;11(4):R59.

98. Fernandez SV, Bingham C, Fittipaldi P, Austin L, Palazzo J, Palmer $\mathrm{G}$, et al. TP53 mutations detected in circulating tumor cells present in the blood of metastatic triple negative breast cancer patients. Breast Cancer Res. 2014;16(5):445. 